\title{
REFINEMENTS OF A TWO-SIDED INEQUALITY FOR TRIGONOMETRIC FUNCTIONS
}

\section{ZHEN-HANG YANG}

Abstract. In this paper, we prove that for $x \in(0, \pi / 2)$

$$
\left(\cos p_{1} x\right)^{1 /\left(3 p_{1}^{2}\right)}<\frac{\sin x}{x}<\left(\cos p_{0} x\right)^{1 /\left(3 p_{0}^{2}\right)}<\cdots<e^{-x^{2} / 6}<\frac{2+\cos x}{3}
$$

with the best constants $p_{1}=0.45346 \ldots$ and $p_{0}=1 / \sqrt{5}$, and the function $p \mapsto(\cos p x)^{1 /\left(3 p^{2}\right)}$ is decreasing on $(0,1)$. Our results greatly refine Adamović-Mitrinović's and Cusa's inequality. As applications, some precise estimations for certain special functions and constants are presented.

Mathematics subject classification (2010): Primary 26D05; Secondary 26A48, 26D15, 33B10.

Keywords and phrases: Adamović-Mitrinović's inequality, Cusa's inequality, trigonometric functions, sharp bound, refinement.

\section{REFERENCES}

[1] G. D. Anderson, M. K. Vamanamurthy and M. Vuorinen, Conformal Invariants, Inequalities, and Quasiconformal Maps, New York 1997.

[2] M. BIERNACKI AND J. KRZYZ, On the monotonicity of certain functionals in the theory of analytic functions, Annales Universitatis Mariae Curie-Sklodowska 9 (1995), 135-147.

[3] D. M. BRADLEY, Representations of Catalan's constant, 2001, available online at http://citeseerx.ist.psu.edu/viewdoc/summary?doi=10.1.1.26.1879.

[4] E. CATALAN, Recherches sur la constante $G$, et sur les intégrales eulériennes, Méoires de l'Academie imperiale des sciences de Saint-Pétersbourg, Ser. 31, 7 (1883).

[5] C.-P. Chen And W.-S. Cheung, Sharp Cusa and Becker-Stark inequalities, J. Inequal. Appl. 2011 (2011), 136.

[6] Group of compilation, Handbook of Mathematics, Peoples' Education Press, Beijing, China, 1979. (Chinese)

[7] C. Huygens, Oeuvres Completes 1888-1940, Socié te Hollondaise des Science, Haga.

[8] K. S. K. Iyengar, B. S. Madhava Rao and T. S. Nanjundiah, Some trigonometrical inequalities, Half-Yearly J. Mysore Univ. Sect. B., N. S. 6 (1945), 1-12.

[9] R. KlÉN, M. Visuri AND M. VUORInEn, On Jordan type inequalities for hyperbolic functions, J. Inequal. Appl. 2010 (2010), Art. ID 362548, 14 pages, doi:10.1155/2010/362548.

[10] Y.-P. LV, G.-D. WANG AND Y.-M. CHU, A note on Jordan type inequalities for hyperbolic functions, Appl. Math. Lett. 25 (2012), 505-508.

[11] D. S. Mitrinović, Limitations en module d'une fonction homographique sur un cercle, Univerzitet u Beogradu. Publikacije Elektrotehničkog Fakulteta. Serija Matematika i Fizika 143-155 (1965), 3-4.

[12] D. S. Mitrinović, Analytic Inequalities, Springer-Verlag, Berlin, 1970.

[13] C. MORTICI, The natural approach of Wilker-Cusa-Huygens inequalities, Math. Inequal. Appl. 14 (2011), 535-541.

[14] E. Neuman, Refinements and generalizations of certain inequalities involving trigonometric and hyperbolic functions, Adv. Inequal. Appl. 1, 1 (2012), 1-11.

[15] E. NEUMAN AND J. SÁNDOR, On some inequalities involving trigonometric and hyperbolic functions with emphasis on the Cusa-Huygens, Wilker and Huygens inequalities, Math. Inequal. Appl. 13, 4 (2010), 715-723. 
[16] E. NEUMAN, Inequalities for the Schwab-Borchardt mean and their applications, J. Math. Inequal. 5, 4 (2011), 601-609; available online at http://files.ele-math.com/articles/ jmi-05-52.pdf.

[17] F. QI, Extensions and sharpenings of Jordan's and Kober's inequality, Journal of Mathematics for Technology 12, 4 (1996), 98-102. (Chinese)

[18] F. QI, D.-W. NIU, AND B.-N. GUO, Refinements, generalizations, and applications of Jordan's inequality and related problems, J. Inequal. Appl. 2009 (2009), Article ID 271923, 52 pages; available online at http://dx.doi.org/10.1155/2009/271923.

[19] F. QI, L.-H. CUI AND S.-L. XU, Some inequalities constructed by Tchebysheff's integral inequality, Math. Inequal. Appl. 2, 4 (1999), 517-528; available online at http://dx.doi.org/10.7153/ mia-02-42.

[20] J. SÁNDOR AND M. BENCZE, On Huygens's trigonometric inequality, RGMIA Research Report Collection 8, 3 (2005); available online at http://www.ajmaa.org/RGMIA/papers/ v8n3/Huygens . pdf.

[21] M. K. Vamanamurthy and M. Vuorinen, Inequalities for means, J. Math. Anal. Appl. 183 (1994), 155-166.

[22] S.-H. Wu AND L. Debnath, A new generalized and sharp version of Jordan's inequality and its applications to the improvement of the Yang Le inequality, Appl. Math. Letters 19, 12 (2006), 13781384.

[23] S.-H. Wu, Sharpness and generelization of Jordan's inequality and its application, Taiwanese J. Math. 12, 2 (2008), 325-336.

[24] S.-H. Wu And A. BÁricz, Generalizations of Mitrinović, Adamović and Lazarević inequalities and their applications, Publ. Math. Debrecen 75, 3-4 (2009), 447-458.

[25] L. ZHU, A source of inequalities for circular functions, Comput. Math. Appl. 58 (2009), 1998-2004. 